\title{
Digital Dustbin - Smart Bins for Smart Cities
}

\author{
Mohit Panjabi, Karan Patel
}

\begin{abstract}
This paper researches around the area of the solution of the garbage disposal and waste management with the help of technology. It gives a detailed model of how we can achieve the goal of 'Clean India' together with the use of sensors, cameras, servers, and even human psychology. With the revolutions taking place all over the world on the subject of the climate crisis and global warmings, it becomes a duty of every citizen to contribute to the future lifestyle. Satisfying all the parameters, at first, past researches have been compared, objectives have been defined and then a working model is thus presented. It has always been difficult to change the mind-set of a whole lot of people, and thus in this research paper, addressing this problem, the solution of such product development is given which satisfies the need of the citizens and also contributes effectively to the waste management system. The model is proved with a prototype, and all the facts\& figures are provided, which are necessary.
\end{abstract}

Keywords: Arduino, digital dustbin, digitalization, garbage disposal, ultrasonic sensor, waste management.

\section{INTRODUCTION}

India today is one of the fastest developing countries and also taking major aggressive steps in waste management. Right from prime minister's 'Swachh Bharat' mission (2014) to Plastic Waste Management rules in 2016 (PWM 2016), E-Waste (Management) Rules, 2016 and the Hazardous and Other Wastes (Management and Transboundary Movement) Rules (2016) and many. The government is leaving no stone unturned to mechanize an effective waste management system across the geography. But is it really happening? The current population of India is $\mathbf{1 , 3 6 9 , 7 8 8 , 4 2 2}$ as 2019, based on Worldometer's elaboration of the latest United Nations data. And if all this 1.4 billion people work together taking one step each, collectively we will take 1.4 billion steps in making our country clean and hygienic. The problem of waste management is not only an environmental crisis, but alsoa psychological issue in human beings. And thus, through this research, a new milestone is achieved in this specific area.

\section{LITERATURE REVIEW}

The notable research work is already done in this field and one of the recent related work is done by S. Zavare and her colleagues [1] on sensornodesconnected to an Arduino board-based control system that uses GSM module to send prior alert messages to the municipality by a server hosting web application.

Revised Manuscript Received on May 20, 2020.

Mohit Panjabi, Mechatronics Engineering, G H Patel College of Engineering \& Technology, Anand, India. E-mail: mohitpanjabi18@gmail.com

Karan Patel, Mechatronics Engineering, G H Patel College of Engineering \& Technology, Anand, India. E-mail: karan11119999@gmail.com

The whole system including a GPS module for tracking the bin and ultrasonic sensor was interfaced with NodeMCU whose built-in Wi-Fi module was used to connect the control system. Apart from all these works, a smart solid waste management system is designed by Trushali $\mathrm{S}$. Vagade and her team [2], that will check status and give alert of dustbin fullness and more significantly system has a feature to literate people to use dustbin properly and to automatically sense and encourage to clean garbage present outside the dustbin. This research was mainly based on signaling municipality and maintaining city hygiene through a smart dustbin. But another work done by Rishabh Kumar Singhvi and his team [3] in implementing a system based on Internet of Things (IoT) that cannot only send a message to the corporation about the overflow and toxicity level of the dustbins but also a website is also developed to supervise the data related to the dustbins. The message is sent using the GSM module to the mobile phone and data related to the dustbin status is updated on the website. On this website, citizens can also submit complaints related to dustbin or waste management. In the recommended system, Arduino is used as a microcontroller to interface between GSM/GPRS module with Ultrasonic and gas sensors that are used for measurement of level and toxicity respectively. Moving further, research on Smart Bin Implementation for Smart Cities done by Narayan Sharma, Nirman Singha, and Tanmoy Dutta is a work of consideration. They didn't create a smart bin, but enabling sensors on them, they connected many smart bins throughout the area with the help of the cellular network, which helped in analyzing a large amount of data about waste management around the city [4].

When we are talking about user-friendly developments, considerable work is done in this by Ahmed Imteaj and his team [5]. This system being an android based application where the user himself can contribute to clean his city, it notifies volunteers to come forward so that they can inform the city corporation. The amenities of this application are - it enables the user to detect nearby dustbin's location with path, helps to see an available volunteer on the map, notify them usinggoogle push service notification and guides them on how to submit a report to authorities if a problem arises.

All this work has been done on notifying municipality and volunteering and maintaining hygiene problems, but the main psychological area was left untouched. It has always been a human tendency to ignore things that won't satisfy their greed in any way, and so in this research paper, we have developed a system that can not only notify the municipality when it is full but also attracts the users by giving them some credits per usage. This system is sensor interfaced and works on QR code scanning which opens the lid of the dustbin automatically when a user approaches as well as instructs the user how to use dustbin through LCD display. 


\section{Digital Dustbin - Smart Bins for Smart Cities}

It works on the mobile application to store the credited points given by the dustbin.

III. PERIPHERALS TO BE USED

Table-I: Components and their Specifications

\begin{tabular}{|c|c|}
\hline Components & Specifications \\
\hline ArduinoUno & GenericUnoR3 \\
\hline Microcontroller & ATmega328P \\
\hline Bluetooth Module & HC-05 \\
\hline GSM Module & SIM800L GPRS \\
\hline High Torque Servo & Mg996R Metal Gear \\
\hline Motor & Servo \\
\hline QR Scanner & - \\
\hline LCD Display & $16 \times 2$ character \\
\hline Load Cell & 3 kg load cell \\
\hline Ultrasonic Sensor & HC-SR04 \\
\hline Rechargeable battery & Li-Po 12V \\
\hline Power Modulator & - \\
\hline Solar Panel & - \\
\hline
\end{tabular}

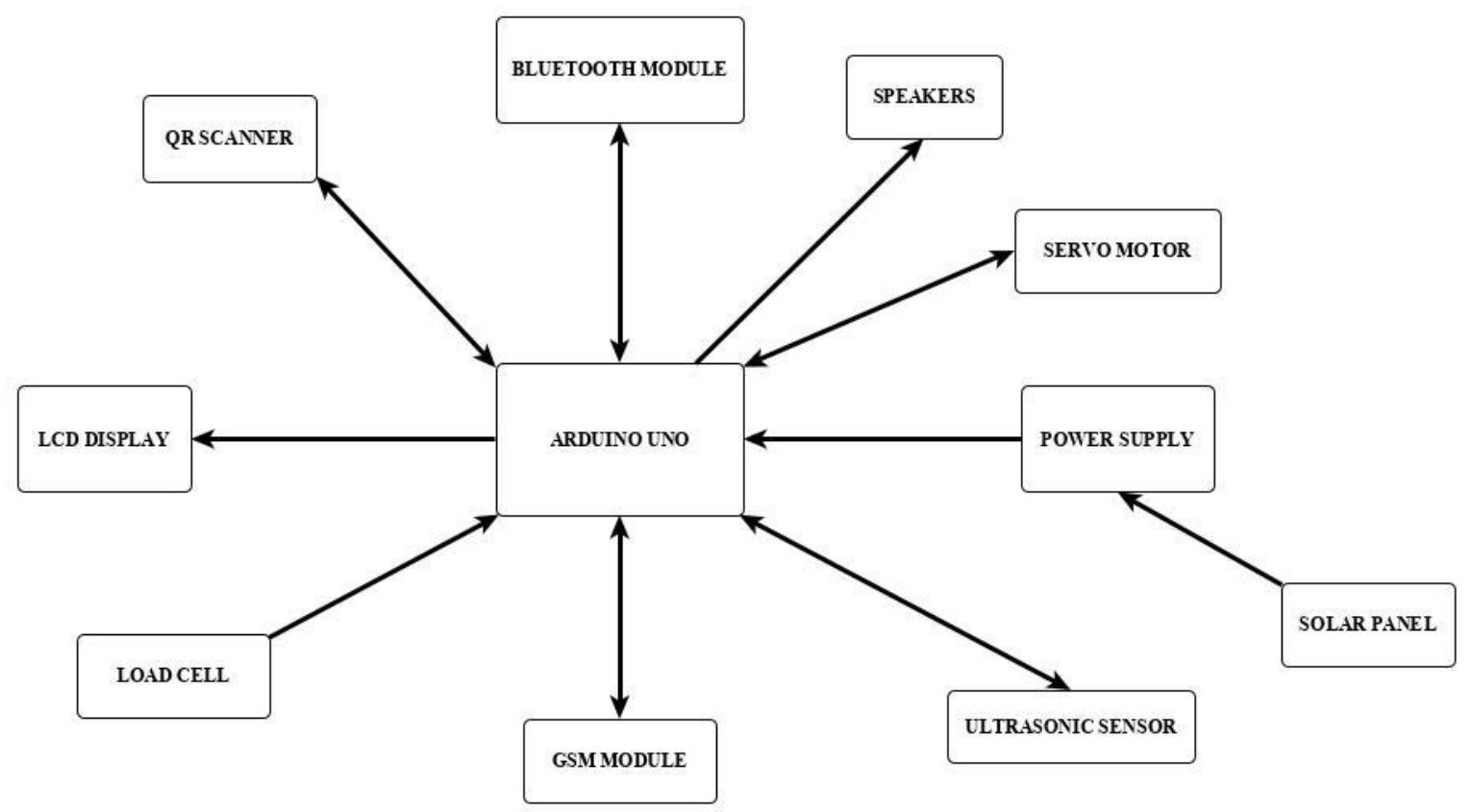

Fig. I. Interfacing of components with Arduino.

\section{METHODOLOGY}

In this paper, we have tried to cover the loopholes created in prior researches in this field. The features and specifications involved in this development include a digital dustbin which detects human with the help of ultrasonic sensor and guides him by giving instruction using speakers and LCD display. After the user shows his QR code of Aadhar card on the scanner, the window of the dustbin opens for collecting waste until the person is standing there. The system will read the data from QR code, analyze the amount of waste using sensors and based on that the user will be credited some limited discount points once a day. Dustbins placed near gardens can offer free $\mathrm{Wi}-\mathrm{Fi}$ to the users for the decided time so that they can enjoy Wi-Fi while sitting in the garden. When the dustbin is full, another ultrasonic sensor detects the threshold level and notifies higher authorities. The components we have used in the making of this dustbin are all mentioned in the Table-I with their specifications. As shown in the block diagram below, a microcontroller Arduino Uno was chosen as the central controller unit of the system, interfaced with Bluetooth Module, Ultrasonic Sensor and Servo motor. A load cell was used to calculate the weight of the waste thrown by the user, by converting the force and pressure of the waste into electrical signals, which in return was displayed as an output through LCD display. 
The power supply was given to the microcontroller, speaker, QR scanner and GSM Module. This power supply was generated via solar panels. The working of the whole system can be explained as when a human being is detected by the ultrasonic sensor, the display and speakers will guide the being to connect Bluetooth and share the unique Aadhar card QR code. If the user scanned the code successfully, the bin's window will open to accept the waste. If the user is unable to scan the code, the display will again restart messages. The waste is then analyzed and if user visits for the first time, some points are credited with acknowledgment message for the user, if the user has visited before the same day, points will not be credited to him. And the window will get closed. The algorithm of working of this digital dustbin is as shown below:

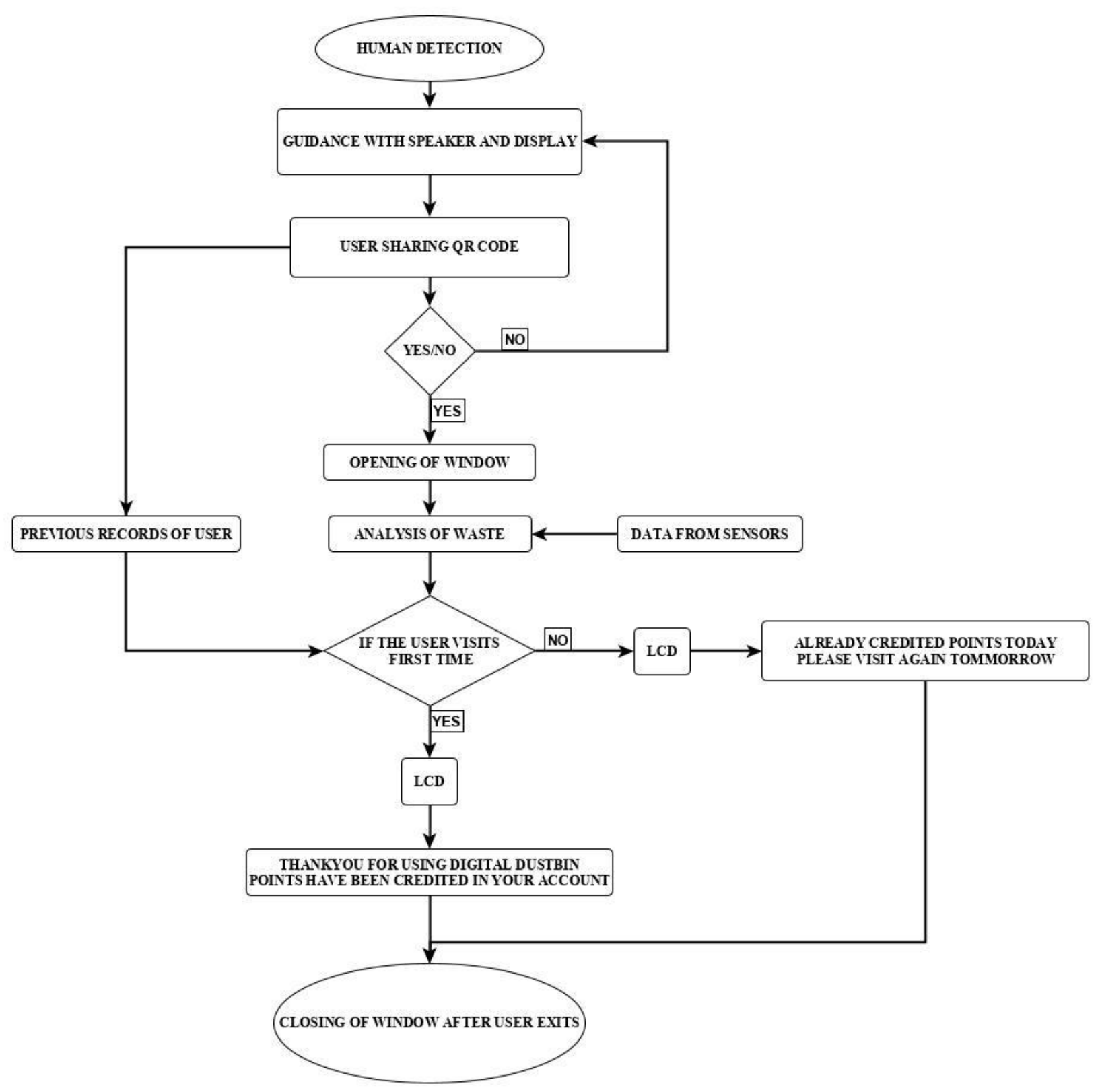

Fig. II. Flowchart of Working Algorithm.

It also supports Wi-Fi modulation, which can be used to provide free Wi-Fi to the users of the bin located near some garden or public place for a certain amount of time. Thus, this system is much more user-friendly and well maintained. Expanding the areas of its utility, we can also make it detect nuclear radiations when used at places like stations and airports so that bombs can be avoided if any. The prototype model and the mobile application of the mentioned methodology is as shown in the Fig.III: 
Digital Dustbin - Smart Bins for Smart Cities

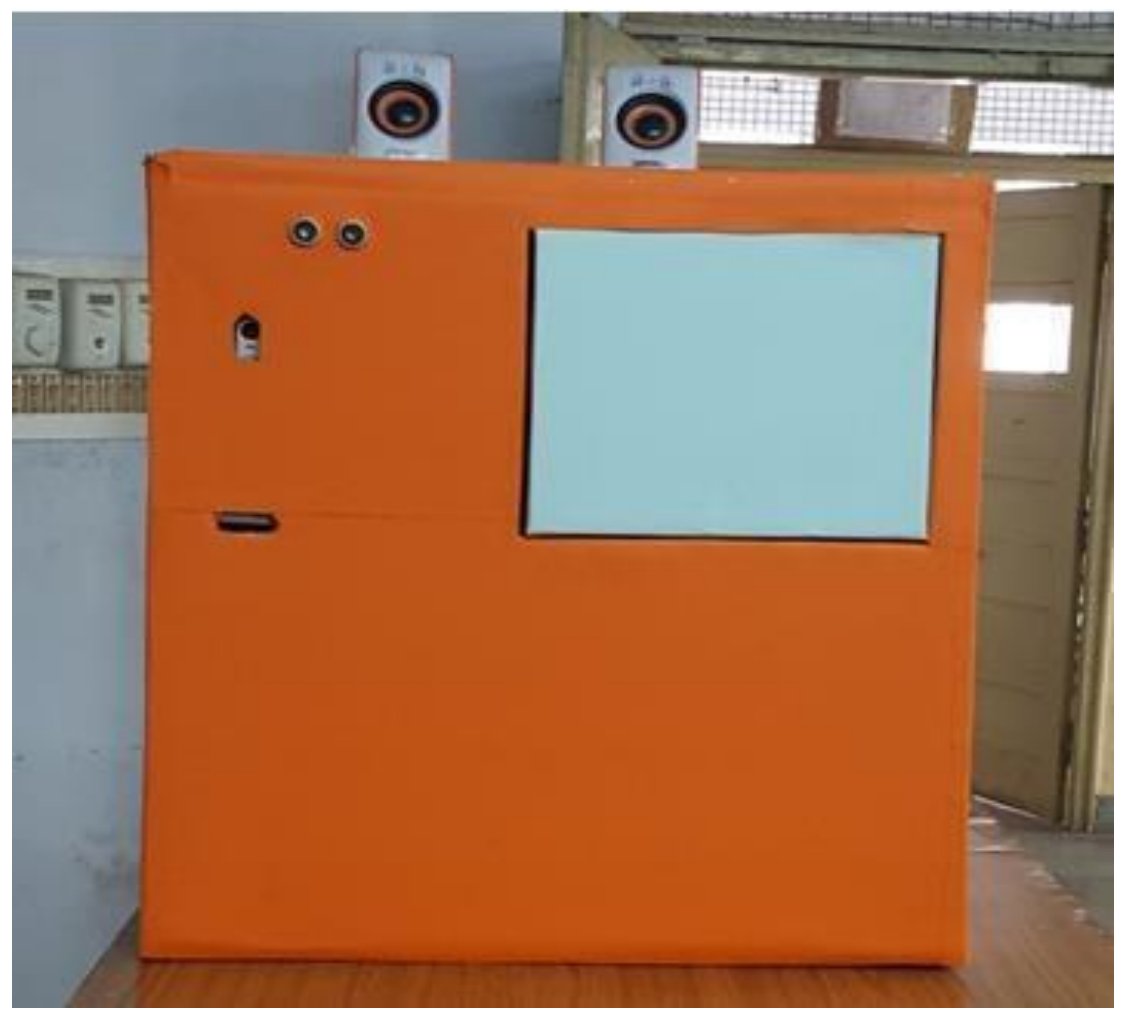

Fig. III. Prototype of the Digital Dustbin.

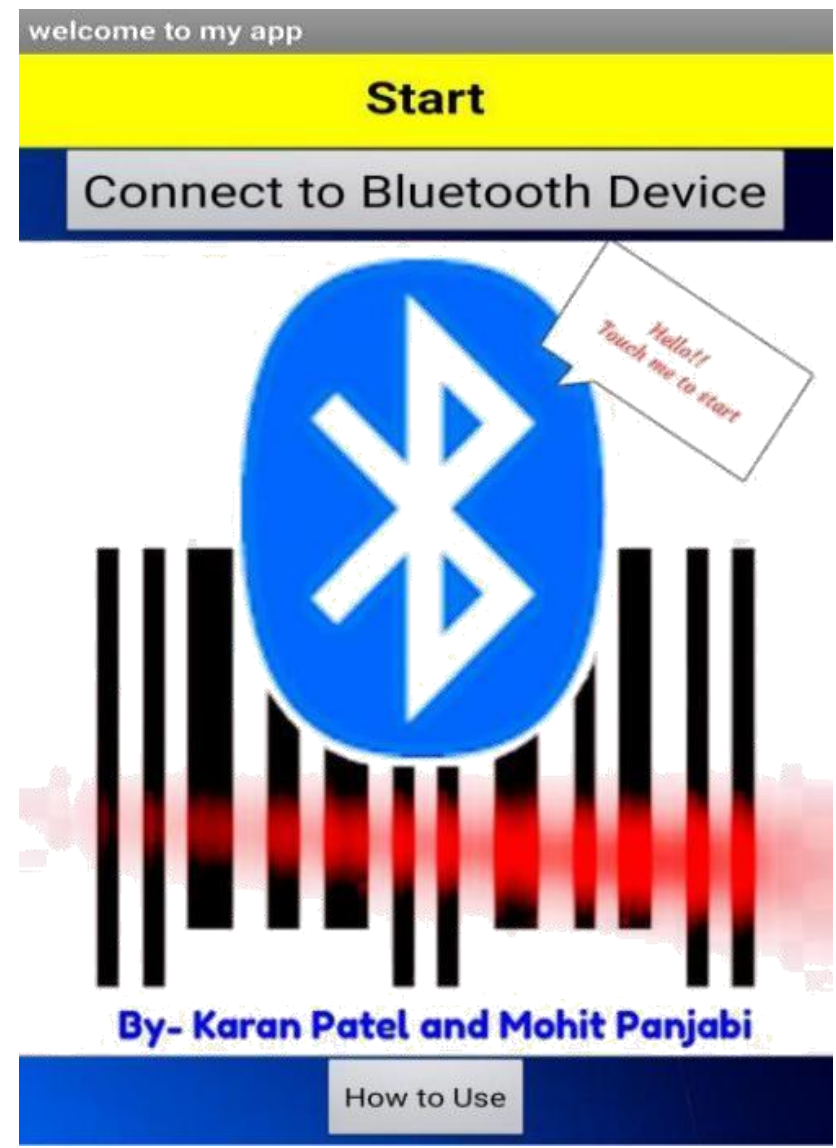

Fig. IV. Screenshot of the Application. 
Table-II Comparison of features, technologies and specifications among the existing smart dustbins with the Digital Dustbin

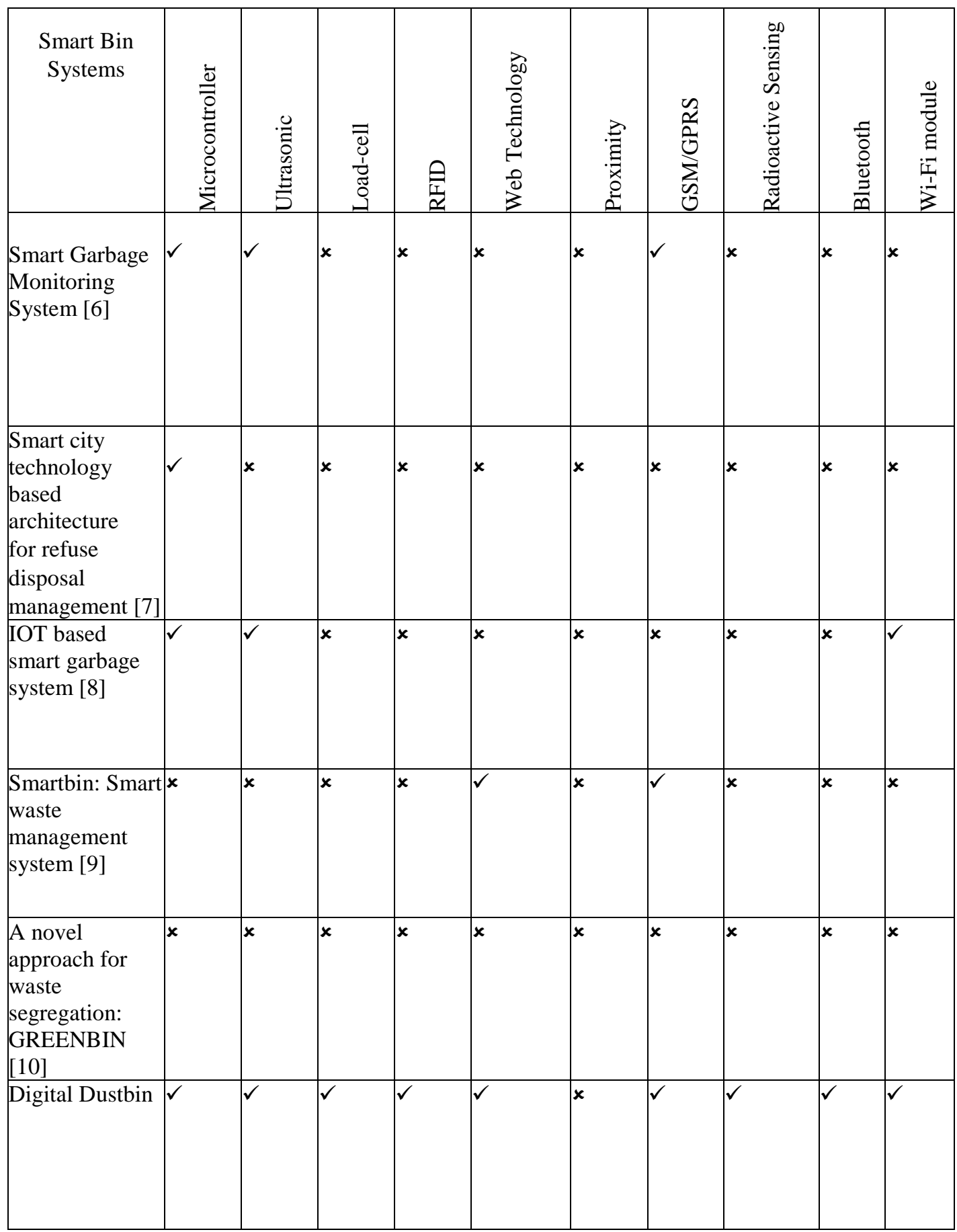

As mentioned in the above table, digital dustbin has more features and technologies embedded and is more user-friendly than many existing systems.

\section{RESULTS}

The current model is equipped with ultrasonic sensor which opens the passage of dustbin when a user approaches. Usage of ultrasonic sensor and load-cell is done as to achieve maximum but accurate requirements of the smart dustbin. Furthermore, Wi-Fi module and Bluetooth module allows to interact with users and attract them. Radioactive Sensing enables the detection of any kind of radioactive or dangerous substance as safety of the city has become quite a concern now-a-days. With the increasing use of smart phones, web technology proves to be easy going to any aged person.

\section{CONCLUSION \& FUTURE SCOPE}

The system integrated here is user-friendly as well as ecofriendly as it works fully on solar energy. It will be easier to attract users and thus, the mission of cleanliness can be well accomplished. Many terrorist attacks can be prevented by these dustbins. The only thing which makes this model unique is its focus is balanced between user and objective achievement. Looking forward to the future scopes we can also interface various ID proof linking other than Aadhar Card, reduced its response 
time, making water proof circuit and body design, building a Human Machine Interface using controller and advanced Nuclear detector.

\section{REFERENCES}

1. S. Zavare, R. Parashare, S. Patil, P. Rathod, and P. V. Babanne, "Smart City Waste Management System Using GSM," Int. J. Comput. Sci. Trends Technol., vol. 5, no. 3, pp. 74- 78, 2017.DQQ.

2. Trushali S. Vasagade, Shabanam S. Tamboli, Archana D. Shinde, "Dynamic solid waste collection and management system based on sensors elevator and GSM", Inventive Communication and Computational Technologies (ICICCT) 2017 International Conference on, pp. 263-267, 2017.

3. Rishabh Kumar Singhvi, Roshan Lal Lohar, Ashok Kumar, Ranjeet Sharma, Lakhan Dev Sharma, Ritesh Kumar Saraswat, "IoT BasedSmart Waste Management System: India prospective", Internet of Things: Smart Innovation and Usages 2019 4th International Conference on, pp. 1-6, 2019.

4. Narayan Sharma, Nirman Singha, Tanmoy Dutta, "Smart Bin Implementation for Smart Cities", International Journal of Scientific \& Engineering Research, Volume 6, Issue 9, September-2015 ISSN 2229-55

5. Ahmed Imteaj, Mahfuzulhoq Chowdhury and Md. ArafinMahamud, "Dissipation of Waste using Dynamic Perception and Alarming System: A Smart City Application", 2nd Int'l Conf on Electrical Engineering and Information \& Communication Technology (ICEEICT) 2015 Jahangirnagar University, Dhaka-1342, Bangladesh, 21-23 May 2015.

6. NorfadzliaMohd Yusof, AimanZakwanJidin, Muhammad Izzat Rahim, "Smart Garbage Monitoring System for Waste Management", MATEC Web of Conferences 97, 01098 (2017), https://doi.org/10.1051/matecconf/20179701098

7. Joke O. Adeyemo ; Oludayo O. Olugbara ; Emmanuel Adetiba, "Smart city technology based architecture for refuse disposal management", https://ieeexplore.ieee.org/document/7530704

8. N. Sathish Kumar ; B. Vuayalakshmi ; R. Jenifer Prarthana ; A. Shankar, "IOT based smart garbage alert system using Arduino UNO”, https://ieeexplore.ieee.org/document/7848162

9. Folianto, Fachmin et al. "Smartbin: Smart wastemanagement system." 2015 IEEE Tenth InternationalConference on Intelligent Sensors, Sensor Networks and Information Processing (ISSNIP) (2015): 1-2.

10. R. Rajkamal, V. Anitha, P. G. Nayaki, K. Ramya and E. Kayalvizhi, "A novel approach for waste segregation at source level for effective generation of electricity - GREENBIN," 2014 International Conference on Science Engineering and Management Research (ICSEMR), Chennai, 2014, pp. 1-4.

\section{AUTHOR'S PROFILE}

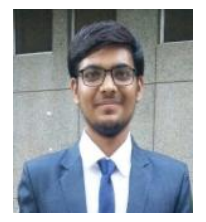

Mohit Panjabi, Mechatronics Engineer, Technical Head of Prarambh Robotics Club and student coordinator of Institute of Innovation Council, G H Patel College of Engineering \& Technology.

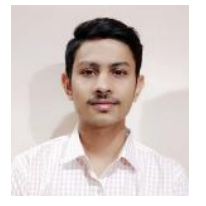

Karan Patel, Mechatronics Engineer, been a head of IEDC, member of Minion Robotics Club, led a state level conference, volunteered in Prarambh Club, G H Patel College of Engineering \& Technology. 